\title{
Martin Fierro y Claridad: Identificación de las corporeidades inscriptas en sus páginas
}

\author{
Martin Fierro and Claridad: Identification of the bodies inscribed on its pages
}

\author{
Gonzalez Aracelli, Marcela Arpes, Alejandro Gasel \\ gonzalez.aracelli@yahoo.com \\ Universidad Nacional de la Patagonia Austral \\ Unidad Académica Río Gallegos
}

Recibido: 20/02/2019. Aceptado: 05/07/2019

\begin{abstract}
RESUMEN
En el presente trabajo analizamos la inscripción de la corporeidad en la revista Martín Fierro, desde sus inicios en 1924 hasta su último número en 1927, al mismo tiempo que trazamos una línea comparativa con Claridad, revista que se autodefine como tribuna del pensamiento de izquierda. La corporeidad como campo que articula la ya conocida disputa entre dos espacios representativos del ambiente intelectual y cultural de Buenos Aires en la década del 20, se trama en el enfrentamiento o la oposición entre los grupos de Boedo y Florida. De manera que su inscripción en ambas revista está atravesada por la estética de las vanguardias históricas y políticas que dibujan al interior de las páginas corporeidades que se modulan a partir de la experimentación, renovación, enfrentamientos, pero también por la búsqueda de representaciones que cristalicen imágenes de la identidad nacional o la resistan.

Con el fin de realizar dicho análisis esbozamos una propuesta para el estudio de revistas de arte y cultura que se desprende de una consideración inicial: la hoja en blanco es un espacio de disputa; la selección y preponderancia, o no, de determinado elemento paratextual obedece a posicionamientos particulares.
\end{abstract}

Palabras clave: Revistas; Corporeidad; Dispositivos enunciativos

\begin{abstract}
In this paper we analyze the inscription of the bodies in the magazine Martin Fierro, from its beginnings in 1924 to its last number in 1927, at the same time that we draw a comparative line whit Claridad, a magazine that self-defined itself as a tribune of leftist thought. The corporeality as field that articulates the already known dispute between two representative spaces of the intellectual and cultural environment of Buenos Aires in the decade of the 20's, is woven in the confrontation or the opposition between the groups of Boedo and Florida. So that its inscription in both magazines is crossed by the aesthetics of the historical and political vanguards that draw inside the pages corporeities that modulate from experimentation, renewal, confrontations, but also by the search for representations that crystallize images of national identity or resist it.
\end{abstract}


In order to carry out this analysis, we outline a proposal for the study of art and culture magazines that comes from an initial consideration: the blank page is a space for dispute; the selection and preponderance, or not, of a given paratextual element is due to particular positions.

Key words: Magazine; corporeality; enunciative devices.

\section{INTRODUCCIÓN}

Las revistas de arte y cultura durante la década del veinte fueron un instrumento de suma importancia para nuestra literatura, impulsaron la renovación de las artes desde varias disciplinas, y más aún, en sus páginas encontramos las evidencias de que las vanguardias latinoamericanas readecuaron los movimientos estéticos europeos a los tópicos y problemáticas propias de nuestra América. Y, en general, las revistas han sido una herramienta relevante que acompañó el surgir de nuevas ideas en las sociedades.

En particular, los dos ejemplares que seleccionamos, Martín Fierro y Claridad, remiten al momento de modernización de nuestro país a partir del cambio paradigmático que marcó la Guerra Mundial. Es posible leer este proceso en el que el cuerpo se vuelve la realidad material de la vida social y cultural, donde deviene metáfora de las problemáticas que se presentan en su actualidad inmediata. De manera que, planteamos como meta general sentar las bases para un análisis de los modos de inscripción de lo corpóreo en las revistas culturales en tanto textos colectivos y públicos cuya praxis inmediata se encuentra en el momento de publicación, pero posteriormente, se convierten en testimonios, documentos que atestiguan políticas, novedades, ideas y controversias.

Para desarrollar esta meta consideramos que las revistas deben ser estudiadas desde estas dos perspectivas: el presente de la publicación que intenta intervenir su coyuntura cultural inmediata, y como documento histórico que las inserta en una historia de la cultura. Diseñar un método de análisis de estos objetos que se sitúan en una doble perspectiva no puede dejar de considerar las estrategias políticas, culturales y sociales detrás de cada elemento paratextual. Esta es una de las partes constitutivas del presente análisis, plantear en un primer momento la metodología con que abordaremos el objeto de estudio.

Posteriormente, retomaremos las conclusiones obtenidas en el anterior trabajo de investigación "Inscripción de los cuerpo en la revista Martín Fierro" para profundizar y plantear a partir de ellas las comparaciones o envíos que nos permitirán entablar relaciones de continuidad o disputa con la revista Claridad a los fines de ofrecer un panorama más completo de lo que fueron las vanguardias en nuestro país. Desde ya mencionamos que la inscripción de la corporeidad estará determinada por los dispositivos enunciativos, y los diversos matices semióticos que materializan las diferencias en los posicionamientos de ambos grupos.

\section{MARCO DE REFERENCIAS}

Exponemos en principio una descripción histórico-referencial para enmarcar las circunstancias de producción, circulación y reconocimiento (Verón; 1993, 127) de ambas revistas. Realizamos esto a partir de un rastreo de una serie de artículos que se han publicado 
con respecto al tema y que configuran antecedentes importantes para el presente trabajo. En un segundo momento, presentamos los conceptos teóricos que articularemos en la propuesta de análisis de las revistas culturales.

\section{1. Antecedentes}

Al describir los primeros años de siglo XX, O. Terán señala la Primera Guerra Mundial (1914-1918) y la Revolución Rusa (1917) como dos acontecimientos que tuvieron grandes repercusiones en todo occidente; marcaron un quiebre en el avance optimista de la civilización, y generaron diversas respuestas en el ámbito cultural $(2015,191)$. Inauguraron un nuevo tiempo, ensancharon el mundo y desestructuraron los órdenes tradicionales (Funes; 2006, 50). En nuestro país, el ascenso del Yrigoyenismo al gobierno en 1917 significó el fin de una etapa liderada por la elite oligárquica, y marcó el ascenso de otro sector (Terán; 2015, 192) integrado por sectores obreros que en su mayoría derivaban del proceso de inmigración implementado a fines del siglo anterior.

En este marco, la difusión de las ideas y la "nueva sensibilidad" del "hombre nuevo" que se plantea frente a los vacíos que dejan los conflictos bélicos se difunden en la sociedad a través de los distintos medios de prensa, principalmente por diarios y revistas que adoptan actitudes tan diversas como las ideologías en las que se sustentan.

Mateo Haymes $(2011,75)$ analiza la actitud que las vanguardias adquieren, en nuestro país ${ }^{1}$, respecto de las industrias culturales que desde las primeras décadas del siglo XX se fortalecieron provocando cambios en los escritores, las formas de escribir, y el público que los consumía. El grupo que nuclea la estética de vanguardia reside en la revista Martin Fierro, cuyo movimiento con respecto al mercado literario oscila entre la ruptura y la adaptación: buscaban marcar la diferencia con respecto a la consolidación de un tipo de literatura que a expensas del resiente centenario de la Revolución independentista eclipsaba la producción escrita. Al mismo tiempo, por las características del campo intelectual en el que la mayoría de los escritores pertenecían a la oligarquía, sus creaciones reclamaban un tipo particular de público que pudiera entender o apreciar el artificio estético. Pero, para legitimar esas producciones necesariamente, los escritores de la "nueva generación", debieron acudir al mercado y la industria de las que deseaban alejarse pues la academia no les otorgaría la legalidad que necesitaban. Así, los martinfierristas entablaron relaciones de atracción y repulsión con el mercado de los bienes culturales.

Con un análisis más centrado en las cuestiones del estilo, Ruben Hitz (2008; 65) expone las especificidades de la revista en cuanto a la novedad en el diseño con el fin de destacar la innovación que introduce Martín Fierro en tato dispositivo comunicacional renovador. Al describir las características del formato y estilo vincula la materialidad (Verón; 2013,143-149) con los efectos producidos en el lector: el tamaño tabloide, el diseño de las páginas con imágenes acompañando cada texto, los pequeños motivos de origen precolombino usados a modo de decoración, entre otros, resultan funcionales a la demanda de generar un público que aprecie el artefacto estético.

En relación a los atributos que caracterizan a Martín Fierro como un artefacto grafico novedoso, O. Traversa $(2009 ; 147)$ describe los efectos de lectura generados a partir de "...las adjudicaciones de sentido que otorgamos cuando nos vinculamos con algún soporte que contenga resultados o elementos propios de la escritura, asociados o no con rasgos gráficos...". Señala por ejemplo, la diversidad de técnicas que se aplican en las tapas de la revista a lo largo de los años: el dibujo caricaturesco, la fotografías de las obras de arte y la fotografía de acontecimientos como testimonio de dichos actos. El público lector entabla

\footnotetext{
${ }^{1}$ Cabe aclarar que las vanguardias en nuestro continente al ser una readecuación de los movimientos estéticos europeos a las problemáticas y demandas sociales o culturales de América Latina, adquieren caracteres diversos. En México las vanguardias políticas y estéticas se juntan en un mismo movimiento, mientras que en nuestro país las cosas son distintas. (Schwartz; 1991)
} 
vínculos diversos con el artefacto semiótico, de allí que Traversa defina a Martín Fierro como una revista de experiencia más corporal y de vínculo sensorial antes que literaria.

Por otro lado, al analizar el marco cultural argentino de fines de la década de 1920, Florencia de Cassone $(2008 ; 67)$ se detiene en la polémica político-literaria protagonizada por las revistas Martín Fierro y Los Pensadores (1922-1926) que en la segunda época cambian el nombre por Claridad (1926-1941). Aclara que dicha polémica fue más publicitaria que real pues ambos grupos compartían la misma irreverencia, además de que algunos integrantes colaboraban con ambas revistas. La diferencia entre los grupos identificados con las calles Boedo (Claridad) y Florida (Martin Fierro) estaba en la intencionalidad frente a la producción literaria: el arte por el arte, puro, sin compromisos políticos, enfocado en el artificio estético, en la metáfora como principal característica de la estética ultraísta de los martinfierristas, o, el arte comprometido, producto de las preocupaciones sociales, más realista en su estética, vocero de los recientes movimientos sociales, como lo fue el arte de Claridad.

Interesada en el arte, la literatura, la crítica, la política y la sociología, nacida para integrar un proyecto de política cultural concreto como lo fue la editorial fundada por Antonio Zamora, el primer número de la revista Claridad aparece el 13 de Julio de 1926. Dos eran los temas absorbentes de la predica de Claridad: el primero, el de la revolución social y política bajo la consigna de la izquierda; el segundo, el repudio contra las dictaduras, el militarismo, el clericalismo y el imperialismo (Cassone; 2002,6). Entre las publicaciones en la revista y las ediciones de libros accesibles en la cooperativa, marchaba un proyecto cultural basado en una pedagogía de los sectores populares. El cambio social solo podría lograrse a partir del progreso individual, por lo tanto la educación cumplía un papel fundamental, y la edición de obras desde la cooperativa editorial Claridad apuntaba a formar un público que no solo consuma literatura sino que sea capaz de entenderla.

En esta misma línea, Cedro J. $(2012 ; 47)$ analiza el camino recorrido por el proyecto de Claridad, cuyo mérito estuvo en la progresiva construcción de un puente entre los dos extremos del mundo del libro de la época, ampliando la oferta en el mercado masivo y creando, al mismo tiempo, su demanda (Ídem, 59). Los procesos de inmigración y alfabetización conformaron un amplio público, que si bien no contaban con la formación necesaria para aventurarse en los libros de los locales de la zona céntrica donde circulaba la cultura letrada, demostraron estar ávidos de practicar el hábito de lectura, conformando así el público masivo que consumía las publicaciones de la cooperativa editorial Claridad.

En fin, ambas revistas: Claridad y Martin Fierro, integran proyectos culturales diversos. Surgen de las mismas circunstancias sociales y políticas, pero una decide centrarse en la formación e innovación estética mientras que la otra prefiere la formación pedagógica de un público también diverso.

Exponemos, a continuación, una serie de conceptos que articulados entre sí nos permitirán analizar nuestro objeto de estudio reconstruyendo, desde las páginas, una descripción particular del enfrentamiento o continuidad temática entre las revistas seleccionadas.

\section{2. Anclajes teóricos}

Abordamos las revistas culturales a partir de la teoría de los discursos sociales planteada por Eliseo Verón $(1993,125)$ como un conjunto de hipótesis sobre los modos de funcionamiento de la semiosis social en tanto que las páginas de las revistas están cargadas de significaciones y participan en ese proceso de semiosis donde toda producción de sentido es social y todo fenómeno social es un proceso de creación de sentido.

El mismo autor señala que toda producción de sentido tiene una manifestación material que constituye fragmentos de semiosis (Ídem, 126-127). Es decir, toda comunicación humana está "mediada" ya que el sentido solo puede circular materializado como resultante de una secuencia de operaciones técnicas (Verón; 2013, 143-149). Al retomar estas consideraciones O. Traversa (2014) define y caracteriza la noción de dispositivos, en las instancias de 
enunciación, resaltando las inflexiones o variaciones que pueden provocar con respecto al sentido.

Cualquier recurso que se ponga en obra para participar del intercambio discursivo lo hace por medio de artefactos integrados por diferentes técnicas; a esas asociaciones O Traversa las designa como dispositivos (Ídem, 12). En tanto cumplen una función vincular, gestionan las instancias de contacto entre las materias sensibles y las adjudicaciones de sentidos, los dispositivos enunciativos cumplen la función de ser mediadores (Traversa 2001, 235-236). Partimos de estas consideraciones iniciales porque consideraremos nuestro objeto de estudio a partir de la noción de dispositivos enunciativos que tematizan diversas maneras de lo corpóreo: las tapas de las revistas, las fotografías recuerdos, la reproducción técnicas de obras de arte, y el texto en sus diversos tipos, modulan corporeidades que adquieren sentidos diversos.

Para complementar este análisis necesitamos precisar otra noción que es clave ya que es en la prensa gráfica donde más se explota: las concepciones sobre el paratexto, que por su naturaleza heterogénea exige un abordaje multidisciplinario (Alvarado; 1994, 10). De las variadas definiciones resaltamos aquella que considera al paratexto como dispositivo pragmático que predispone o condiciona la lectura, al mismo tiempo que la acompaña cooperando con el lector en la construcción del sentido (Ídem, 16). Adoptamos una clasificación que contempla dos modos que pueden mezclarse entre sí: el paratexto icónico y el paratexto verbal, aunque también consideraremos las modalidades de la materialidad en tanto soporte que delimita el sentido y la circulación de las revistas.

Por último, retomamos dos conceptos planteados por B. Sarlo $(1992 ; 9-16)^{2}$ con el fin de especificar el porqué de las nociones expuestas anteriormente.

La organización de los textos en las revistas, las imágenes o ilustraciones que los acompañan, los titulares de primera plana, el índice, todo, en conjunto conforman la sintaxis de la revista, a la que Sarlo $(1992,10)$ define como un ejercicio de valor. Cada elemento, integrado en la estructura particular de una revista juega un papel importante, las políticas textuales y graficas surgen de una coyuntura ${ }^{3}$ de la que cobran significado. De allí la importancia de los elementos paratextuales como dispositivos pragmáticos (Alvarado; 1994, 16) que introducen inflexiones en el sentido (Traversa; 2014, 7) a través de las operaciones técnicas ${ }^{4}$. Como elementos integrantes de la sintaxis de la revista, es posible rastrear determinados elementos paratextuales que pueden ser analizados como partes constitutivas de la estructura que define a las revistas.

Pero para referirse a las relaciones que todo texto entabla fuera de sí mismo, es decir, vinculaciones con el contexto intelectual en el que se genera, Sarlo $(1992,12)$ utiliza el término de "geografías culturales" como una vía de acceso hacia los imaginarios culturales. Las revistas circulan por espacios específicos, generalmente indicados por el tipo de público al que apelan, los lugares donde son adquiridas, lo que determina, a su vez, el espacio que ocupan idealmente. Esta noción nos permitirá, a partir de las coordenadas otorgadas por la sintaxis de la revista, identificar los espacios físicos de circulación y los imaginarios simbólicos que se conjugan en la disputa Boedo y Florida. Al mismo tiempo que nos otorgará

\footnotetext{
${ }^{2}$ Estos conceptos fueron expuestos en el Informe Científico Técnico "Búsqueda y análisis de los modos vanguardistas de inscribir los cuerpos en la revista Martin Fierro" (2017).

${ }^{3}$ Retomando las consideraciones de Eliseo Verón en La semiosis Social (1993), es posible rastrear las condiciones de producción de un texto a partir de las "huellas" en el objeto significante. La noción de "sintaxis" planteada por Sarlo entabla relaciones con el de huellas, pues las políticas textuales y graficas son marcas de las circunstancias de producción.

${ }^{4} \mathrm{Al}$ referirse al ejercicio técnico que se lleva a cabo en las instancias de mediación o vinculación de los dispositivos enunciativos, O. Traversa $(2001 ; 235)$ aclara que dicho ejercicio hace referencia a operaciones pautadas que instauran operaciones de producción de sentido.
} 
un marco referencial para describir y justificar las maneras en que el cuerpo se vuelve realidad material de la vida social y cultural.

Más allá de los enfoques biologicista sobre el cuerpo, lo cierto es que constituye uno de esos tópicos que atraviesan diversas disciplinas, puede ser abordado desde distintos enfoques y varia su sentido de acuerdo con cada una de ellas y no por ello ser un tema agotado en su estudio. Desde la sociología, Le Breton (2002) considera al cuerpo como el efecto de una elaboración social y cultural, es una estructura simbólica, una superficie de proyecciones; de allí que pueda convertirse en la realidad material de la vida social y cultural dejando entrever imaginarios propios de una época.

Presentamos a continuación una indagación y análisis sobre la manera en que esa corporeidad tematiza la realidad social y cultural de principios de siglo XX a partir del abordaje de dos revistas representativas de la época y sus circunstancias particulares.

\section{RESULTADOS, ANÁLISIS Y DISCUSIONES}

\section{1. Materiales y Método}

Básicamente trabajamos con las dos revistas mencionadas: Martin Fierro y Claridad.

La primera en formato papel disponible en la biblioteca Malvina Perazo en el campus de la UNPA-UARG, aunque también se encuentra disponible en su versión digital en el Archivo Histórico de Revistas Argentinas: http://ahira.com.ar/revistas/martinfierro/mfl2.php .

La segunda solo en formato digital disponible en la página web de la Biblioteca de la Nación:http://catalogo.bn.gov.ar/F/?func=direct\&doc_number=001267836\&local_base=GEN ER .

El trabajo metodológico se inscribe en los lineamientos de un campo clásico de la investigación literaria (Dalmaroni; 2009, 63) en el que a partir de un dispositivo teóricocritico, que pone en juego tesis, categorías o perspectivas de procedencia disciplinaria diversas, se aborda la problemática que inicia la investigación. Cabe aclarar que el término "clásico" no remite a una tradición académica, ni a una tendencia anti-actualista, "...es más bien un modo de identificación y construcción de temas-problemas...y un modo de vinculación de a investigación literaria con las teorías y con los saberes en general..." (Ídem, 69).

\section{2. Propuestas de análisis}

Organizamos la propuesta de análisis a partir de tres objetivos: reconocer los dispositivos enunciativos que tematizan formas de inscribir la corporeidad en las revistas, a partir de esta identificación, considerar los recorridos del cuerpo, es decir, el nivel de ejercicio técnico operado sobre el cuerpo en tanto materia sensible transformada en significado y la variación de sentido que dicho ejercicio imprime en la inscripción de la corporeidad; y por último, precisar las continuidades y diferencias entre los grupos de ambas revistas a partir del cuerpo como construcción simbólica. A los fines de ofrecer un panorama general enfocamos el análisis en las tapas.

\section{2. 1. Pugna de tapas, cuerpos en pugna}

Las tapas de las revistas son artefactos productores de sentido, son dispositivos que cumplen una cualidad funcional de diferenciación y establecimiento de vínculos (Traversa; 2005). Deben diferenciarse de la competencia dentro del espacio en el que circulan dichas revistas y deben establecer un vínculo doble: al interior de sí mismas manteniendo una armonía de forma y contenido con sus páginas, y entablar relaciones con el público existente que las consume o el público potencial ocasional para que se convierta en lector recurrente.

La diferenciación entre las publicaciones se logra por medio de un desplazamiento de la sustancia del enunciado a la enunciación, es decir, lo importante es el modus (Ídem, 2005), las 
estrategias que se despliegan a través de las disposiciones de los recursos paratextuales en las primeras páginas, permiten la singularización respecto de otras publicaciones.

Entre los dispositivos más utilizados para lograr esta diferenciación se encuentra la imagen, paratexto icónico que más llama la atención en los negocios. En este sentido, las tapas de la revista Claridad son las más llamativas:

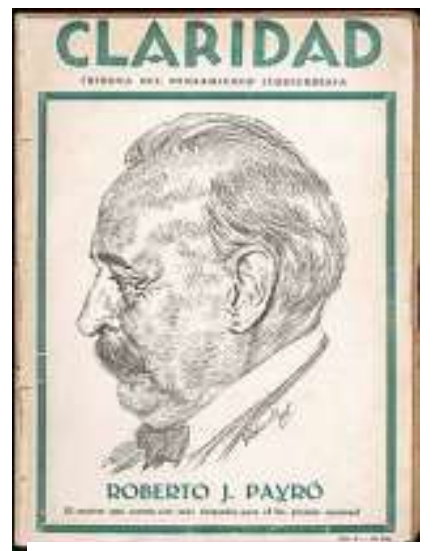

Año I, N $N^{\circ}$

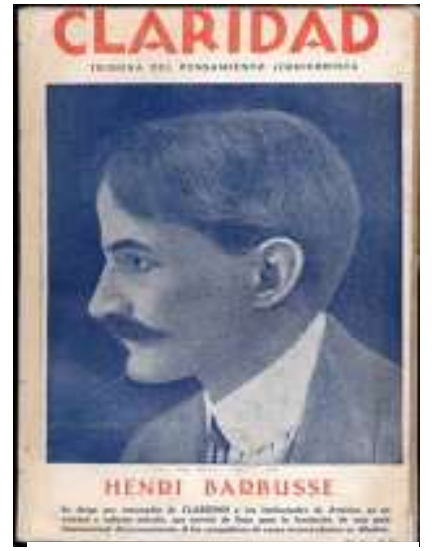

Año IV, $N^{\circ} 130$

Notamos una desproporción en el uso del espacio: evidentemente el centro de las tapas son las imágenes, ocupan el lugar central y el mayor tamaño. El paratexto verbal es mínimo: resalta el título de la revista en la parte superior como titular, combina en color con el breve epígrafe que es el nombre de los personajes en las imágenes; se incluyen también los subtítulos como comentarios que anclan el sentido de las imágenes.

Consecuente con su proyecto cultural, la revista Claridad resalta, en la mayoría de sus tapas, la figura de autores o personajes como estrategia para resaltar determinado contenido dentro de la publicación, orientan la lectura del público para que focalice en el personaje o artículo destacado. Pero al mismo tiempo, consecuente con su metodología pedagógica de educar al pueblo, se proponen estas figuras como especies de modelos o personas importantes a las que no se puede dejar de mencionar, conocer y mirar. Esto es reforzado por el autorretrato que expone el rostro como punto de referencia, atracción, lugar de la mirada.

Distinto es el caso de Martin Fierro, donde los elementos paratextuales guardan una relación de proporción sobre el reducido espacio de la tapa: el título también ocupa la parte superior y el mayor tamaño entre el paratexto verbal, pero a diferencia de Claridad encontramos más presencia de textos, y lo interesante es que la organización paratextual se mantiene constante en todas las ediciones. Claridad varía su edición paratextual en algunos números.

Revisamos algunos ejemplos:

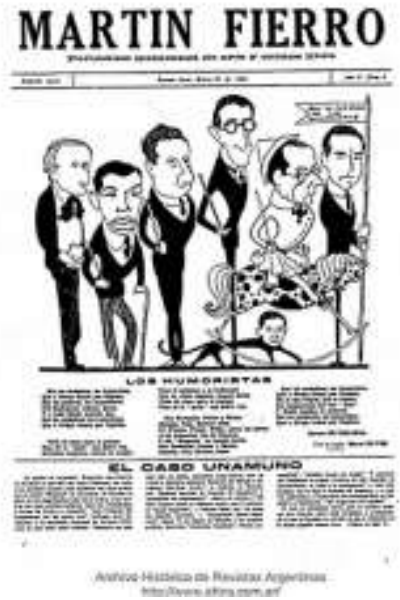

Año I, $N^{\circ} 2$

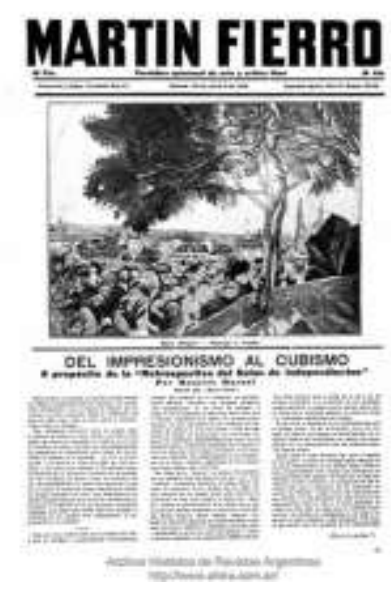

Año III, $N^{\circ} 29-30$ 
Si bien la imagen y el titulo son los encargados de robar la atención del público, una vez capturados, las tapas de Martin Fierro proponen más que artículos destacados, ofrecen poesía, critica, para el lector interesado en temas específicamente artísticos, que posee el tiempo y la comodidad de detenerse a leer las tapas antes de decidirse a comprar la revista. Además, adopta un diseño propio de los diarios: captan al lector pero también proporcionan información.

Una diferencia importante entre los paratextos icónicos utilizados en los primeros números del año I y las siguientes ediciones está en las corporeidades que se inscriben en ellos. Las caricaturas, como dispositivos enunciativos, implementan técnicas de deformación o exageración de los rasgos corporales de los personajes dibujados, el fin inmediato es la risa pero también la crítica. La reproducción de obras de arte, en los números siguientes, tampoco son referencialmente directos con respecto a la corporeidad, es decir, también introducen cambios, implementan técnicas que varían el sentido: no es lo mismo el cuerpo en una obra pictórica, atravesado por la mirada y habilidades del artista, que el cuerpo en una escultura. Cada disciplina artística aborda sus objetos a partir de sus especificidades técnicas, ellas introducen variaciones en el sentido.

Entonces, entre los dispositivos que inscriben la corporeidad en las tapas de las revistas resaltamos la caricatura, como recurso común en ambas publicaciones para introducir la crítica; la fotografía de retratos en Claridad y la de obras pictóricas, escultóricas en Martin Fierro. Aunque ambas remiten a la corporeidad como referencia para llamar la atención del público, la publicación del grupo Boedo resalta el rostro de personajes de la cultura y sociedad, mientras que los del grupo Florida resaltan el cuerpo sometido a las modificaciones que un artista realiza, resaltan un cuerpo estético sometido a la experimentación vanguardista. Distinto es el caso al interior de las revistas: mientras que Martin Fierro mantiene casi el mismo formato que el de la tapa, es decir, titulares, fotografías, caricaturas, todas conviviendo en un mismo espacio; Claridad cambia el formato en su interior: lo preponderante es la escritura, se mantiene el paratexto verbal ya que los titulares, comentarios, subtítulos, varían de tamaño y lugar según la importancia dentro de la publicación. Este detalle es importante para comparar la sintaxis de ambas revistas, es decir, la estructura que organiza los sentidos, pues dependiendo de ella, la inscripción de la corporeidad varia en sus manifestaciones.

\section{2. 2. Vínculos: cuerpo y materialidad del sentido ${ }^{5}$}

Tal como lo mencionamos en apartados anteriores, el sentido necesariamente requiere de una materialidad para circular, ser reconocido e interpretado. Consideramos a las revistas como materialidades donde se despliegan las reglas o técnicas que los diversos dispositivos emplean en la enunciación.

Los dispositivos enunciativos, en tanto adquieren una materialidad. Introducen vínculos diversos entre las instancias de emisión y recepción del sentido (Traversa; 2014, 65). En las publicaciones que analizamos el vínculo es restringido: uno de los cuerpos que participa en la comunicación está ausente, no se trata de un intercambio directo entre dos personas sino que un cuerpo, el público lector, se encuentra frente a un texto, las revistas (Ídem, 67).

La publicación periódica es un tipo de materialidad interesante en la medida en que puede hacer que ese vínculo entre las circunstancias de emisión y las de recepción se prolongue en el tiempo, y que varíe en cada lectura. Pensamos, por ejemplo, en la influencia de la materialidad en la construcción de ese vínculo durante las primeras décadas de siglo XX, en el que a raíz de las circunstancias propias de la época, como los procesos de alfabetización tras las políticas de inmigración, el ascenso al poder de un sector social representativo, en ese entonces, de las clases trabajadoras, hacían que la avidez por la lectura sea una demanda que

\footnotetext{
${ }^{5}$ Tomamos este subtitulo de o. Traversa en Inflexiones del discurso: cambios y rupturas en las trayectorias del sentido. 2014, pp. 65.
} 
las publicaciones periódicas aprovechaban al satisfacer. Incluyendo el auge de las vanguardias y la proliferación de propuestas estéticas ansiosas lanzarse al campo cultural como respuesta a la necesidad de intervenir en su coyuntura.

Pero, pasado el tiempo, el tipo de vínculo que se establece hoy con las revistas culturales es distinto. Primero, a la materialidad en formato papel se le debe sumar la digitalización que rompe con los espacios tradicionales de circulación pues no se ancla a un lugar físico; aunque, incluso dentro del espacio virtual es posible rastrear el lugar por donde circulan las revistas de arte y cultura de la década del 1920, los sitios web de la Biblioteca de la Nación en su archivo digital, los sitios auspiciados por universidades, o en pocos casos, los sitios de transacciones comerciales donde las revistas se ofrecen como mercancías.

Si desde 1920 hasta la década siguiente, tanto Martin Fierro como Claridad eran leídas con avidez por un público interesado en las novedades políticas y estéticas, hoy, las revistas atraen las miradas de los investigadores o especialistas.

No obstante, focalizándonos en las vinculaciones casi inmediatas entre las circunstancias de emisión y de recepción, la construcción de dicha vinculación es diferente en cada revista, y está marcada por los dispositivos enunciativos. Veamos algunos ejemplos para comparar entre las tapas y el interior:
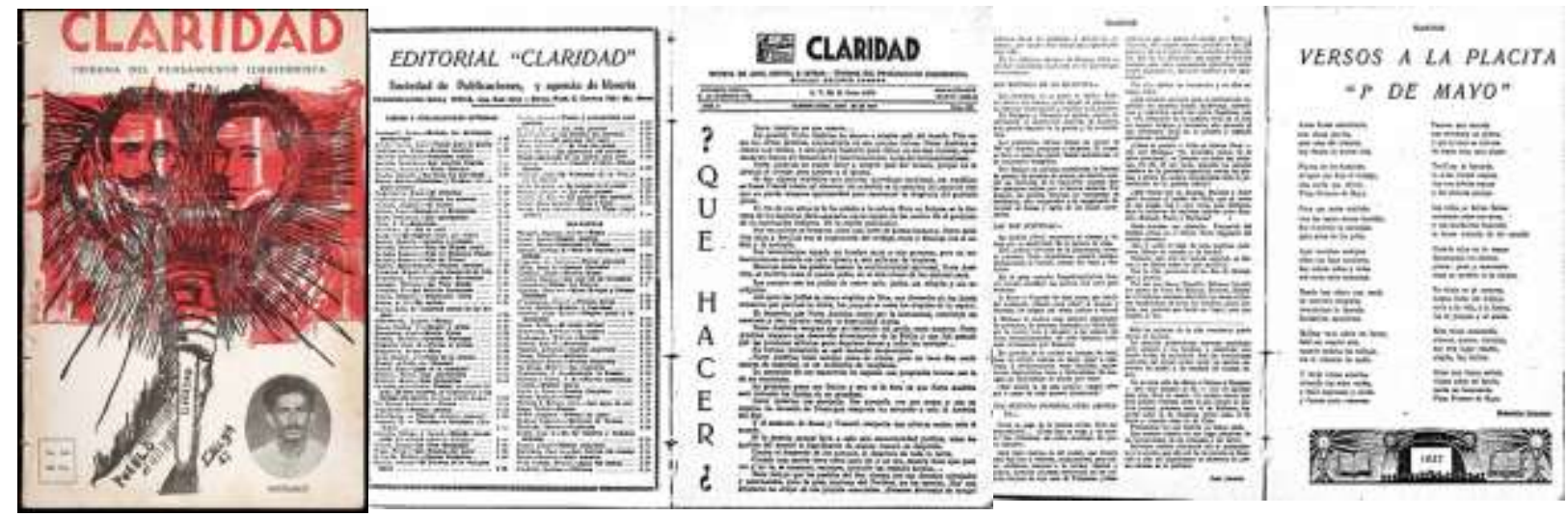

Podríamos llamar vínculo intelectual a la relación que Claridad entabla con su público lector a partir de la escritura como dispositivo enunciativo predominante, específicamente la prosa. Las imágenes son muy pocas en el interior pero ocupan el mayor espacio en las tapas. Esta decisión que hace a la sintaxis de la revista nos permite rastrear sus coordenadas en el campo cultural: adscriptos a la premisa del "arte para la revolución", la temática de los artículos gira en torno al mundo del trabajo, las hostilidades vividas por los inmigrantes, los explotadores y lo explotados; el género que se privilegia es el narrativo construido a partir de la estética realista, incluso en la poesía los temas no escapan de la visibilización de los problemas sociales: "Versos del inmigrante" donde asistimos a la nostalgia de un pobre hombre que añora su tierra natal pero se esfuerza ingenuamente en su nueva vida, "Mi nuevo poema" que nos cuenta la escena cotidiana del ir y venir de la casa al trabajo (Claridad, Año I, $\left.\mathrm{N}^{\circ} 1\right)^{6}$, "Versos a la Placita $1^{\circ}$ de Mayo" que condensa una especie de historia del trabajo en clave poética (C, Año IV, $\mathrm{N}^{\circ} 133$ ).

Según Claridad, el arte debe servir para la revolución, para generar un cambio en las formas de vida social, la protesta, la denuncia, es la culminación del ímpetu artístico (C, Año I, $\mathrm{N}^{\circ} 1$ ). Por lo tanto, el vínculo intelectual que se trama en el proceso de comunicación es el resultado del empleo de la narrativa, la estética realista (incluso en la poesía) y la crítica. La revista apela a educar el pensamiento a partir de la lectura.

\footnotetext{
${ }^{6}$ En adelante nos referiremos a Claridad por su inicial. Las especificaciones bibliográficas se encuentran al final del trabajo.
} 
Por su parte, Martin Fierro apela a la experiencia sensible:

\section{MARTIN FIERRD}

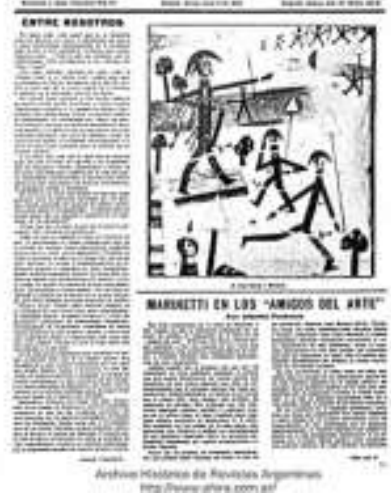

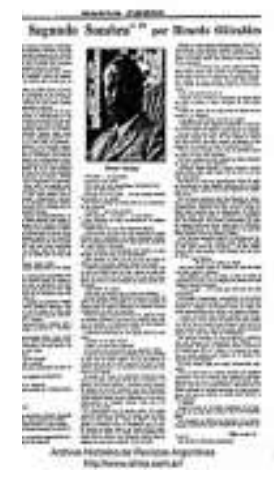

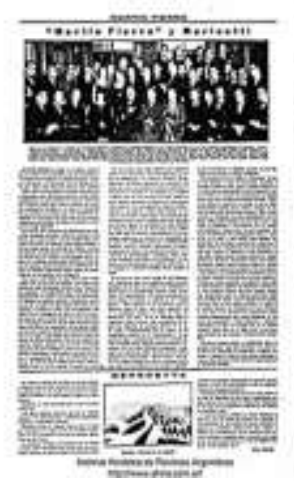

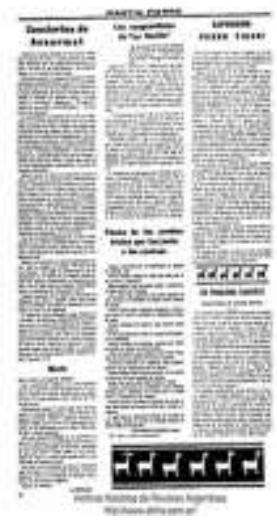

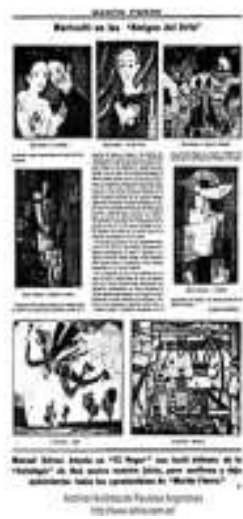

El vínculo que Martin Fierro entabla con su público explota la experiencia perceptiva. La revista plantea un vínculo más corporal y sensible antes que literario (Traversa; 2009, 162). Bombardea al lector con la diversidad de paratextos icónicos, no solo imágenes y fotografías, sino también pequeños motivos decorativos que marcan la finalización de la página o de algún artículo. Además, por su formato tabloide permite una mayor manipulación del material, es más fácil de doblar y desplegar que el formato tradicional de una revista libro.

Martin Fierro es una experiencia estética, reproduce fotografías de obras pictóricas, escultóricas, arquitectónicas, incluso pública artículos de crítica musical. Los colaboradores "educan" el gusto estético del público, presentan las obras de arte y también realizan una crítica, sus artículos retoman las discusiones sobre lo bello, la finalidad de las obras arquitectónicas, la mujer como objeto estético, incluso realizan reseñas de las exposiciones a las que asisten como colaboradores de la revista. Es decir, tenían una presencia activa dentro del campo cultural, participaban en los eventos organizados por instituciones diversas, realizaban sus propias reuniones para agasajar a algún personaje o simplemente para leer poesía.

De manera que, según el tipo de materialidad, la implementación de estrategias paratextuales que son manifestaciones de políticas culturales, modifican los modos de inscripción de la corporeidad en las revistas de acuerdo a los fines propuestos por cada una.

\section{2. 3. Tejido semiótico no degradable}

Pensamos en la metáfora de lo no degradable en tanto las revistas son consideradas actualmente como documentos históricos que condensan un tejido de significaciones que se amplía a lo largo del tiempo, son objetos que no agotan sus sentidos y pueden ser abordados desde diversas disciplinas. Asisten a un acto de enunciación prolongado en el tiempo, sus enunciados llegan incluso hasta nuestros días y se imprimen de nuevos sentidos.

O. Traversa $(2014,72)$ al señalar algunas características de los dispositivos enunciativos describe en ellos la doble inclusión técnica determinada por la temporalidad: una inclusión de orden discursivo, de corta temporalidad en tanto está sujeta a la sintaxis particular de la revista; y una inclusión técnica de alcance social que concierne a la circulación como medio que permite entablar una enunciación prolongada en el tiempo, de allí que las revistas construyan un tejido semióticos no degradable.

$\mathrm{Al}$ analizar este tejido semiótico encontraremos en él las diferencias y continuidades entre los grupos de Boedo y Florida. Partimos desde el análisis del uso del espacio en las páginas, o sea desde la estructura, la sintaxis, para abordar desde allí la distribución imaginaria del espacio público que realizó la década del ’20 (Ledesma; 2009, 192).

Pensamos por ejemplo en la poseía que difunde Martin Fierro en su "sección de lecturas": las mujeres, los espacios, las acciones que describe O. Girondo retratan a las señoritas de clase 
burguesa, que se ornamentan para pasear por las calles y plazas (Martin Fierro; Año I, $\mathrm{N}^{\circ} 2$ ). Los lugares son puntos de encuentro, espacios abiertos o cerrados que propician miradas y conversaciones.

La calle Florida es el lugar perfecto para mirar y ser mirado, lugar del ocio, el deseo, del cultivo de la poesía que exalta la naturaleza, del paseo que permite caminar distraído y observar vidrieras. La configuración simbólica de este espacio en las páginas de Martin Fierro se platea en la disposición de los elementos paratextuales: las páginas de las revistas pueden ser consideradas como la mostración u oferta de artículos artísticos tal como se exhiben en las vidrieras. La mirada del lector recorre las revistas, observa las obras de arte, se detiene a revisar aquellos contenidos que llaman su atención y luego continúa su recorrido.

Mientras que el espacio público con el que se identifica Claridad es la calle Boedo, lugar de transito febril, camino de paso sin detenimientos prolongados que se puebla a determinados horarios. De un ambiente más de barrio que cosmopolita, como una zona arrabalera, el grupo Boedo mira como hito histórico determinante los sucesos de la Revolución Rusa (1917) y los escritores representantes de la estética realista son los modelos en la narrativa.

Aun así, ambas revistas comparten preocupaciones y formas en común. El empleo de elementos paratextuales para diferenciarse una de otra es común en ambas, pero la diferencia está en las imágenes que presentan y la utilidad que le otorga cada una, como los modelos ejemplares que platea Claridad en la presentación de personajes destacados de la cultura y la política, mientras que Martin Fierro destaca las obras de arte influyentes en el ámbito estético. Ambas están a la vanguardia, una adopta el color rojo como representativo de su titular en consonancia con sus posicionamientos ideológicos, la otra se presenta como una galería de imágenes que simulan una exposición artística. Las respuestas a los conflictos y rupturas que plantea la Modernidad a principios de siglo XX puede rastrearse en ambas revistas a partir de la constitución de su materialidad conformada por dispositivos enunciativos que traman corporeidades que lidian entre sí pues una es objeto estético y otra es campo que materializa los conflictos sociales.

\section{CONCLUSIONES}

Finalmente consideramos que el análisis de los modos de inscribir los cuerpos en la revista Martin Fierro y su relación con Claridad implica una variedad de conceptos, teorías y cruces interesantes para un dialogo transdisciplinar.

El uso de determinados dispositivos enunciativos, como las tapas, las fotografías, dibujos, o la escritura, no es una casualidad que deba dejarse librada al azar, cada artefacto, estrategia o elemento paratextual es un índice social que traduce las posibilidades de comunicación de una época determinada en tanto se requiere del empleo de técnicas que constituyen la materialidad.

Además, al abordar el estudio de las revistas culturales es necesario saber que se insertan en una doble temporalidad y en relación a ella las técnicas empleadas se imprimirán de sentidos diversos haciendo que este tipo de publicaciones resista la indiferencia y el paso del tiempo.

El cuerpo en su inscripción estética en la revista Martin Fierro demanda dispositivos que apelan a la mirada, a la estimulación y construcción de una nueva sensibilidad que no teme la experimentación de técnicas nuevas: la reproducción de obras pictóricas recorre desde el cubismo, el expresionismo, surrealismo, entre otras formas del arte que buscan una expresión distinta y singular.

El cuerpo en su inscripción didáctica, ejemplar, como lo son los personajes destacados en las tapas de Claridad, está atravesado por las ideologías de izquierda, que representadas en el color rojo, rodean el autorretrato. El rostro es el foco de la mirada. 


\section{BIBLIOGRAFÍA}

ALVARADO, M. Paratexto (Enciclopedia Semiológica Fonética). Buenos Aires. Universidad de Buenos Aires. 1994.

BIANCHI, L. CYTRYN L. y UBERTALLI F. Claridad: seis décadas de historia editorial. Disponible en: https://www.bn.gov.ar/conferences-files/Boh8nqYmPg7f2ouvSUIsaIj MCBsP3Dk5LKZh98Zs.pdf.

CASSONE, F. "Boedo y Florida en las páginas de Los Pensadores". En: CUYO. Vol. 25/26. P. 59-122. 2008. Disponible en: http//bdigital.uncu.edu.ar/3709.

CASSONE, F. Roberto Arlt y Claridad. En: Revista de Literaturas Modernas. $\mathrm{N}^{\circ} 32$. Mendoza. 2002.

CEDRO, J. El negocio de la edición: Claridad 1022-1937 (en línea). Primer Coloquio Argentino de Estudios sobre el Libro y la Educación. 31 de Octubre, 1 y 2 de Noviembre. La Plata. En Memoria Académica. 2012.

DALMARONI, M. La investigación literaria. Santa Fe. UNL. 2009.

HAYMES, M. G. "Una vanguardia conservadora. La revista Martín Fierro ante la emergencia de las industrias culturales (1924-1927)". Universidad de San Andrés. En: Letras Históricas. $\mathrm{N}^{\circ} 4.2011$

HITZ, R. "Martín Fierro en la vanguardia argentina". En: Elizalde, L. (coord.). Revistas culturales latinoamericanas (1920-1960). México D. F. Consejo Nacional para la Cultura y las Artes, Estados Unidos Mexicanos. 2008.

LE BRETON, D. Sociología del cuerpo y modernidad. Buenos Aires. Nueva Visión. 2002.

SARLO, B. "Intelectuales y revistas: razones de una práctica". En: América: Cahiers du CRICCAL. $\mathrm{N}^{\circ}$ 9-10. Le discourscultureldans les revues latinoaméricaines. 19401970. 1992. https://doi.org/10.3406/ameri.1992.1047

SCHWARTZ, Jorge, Las vanguardias latinoamericanas. Madrid. Cátedra. 1991.

TERÁN, O. Historia de las ideas en la Argentina: Diez lecciones iniciales (1810-1980). Buenos Aires. Siglo Veintiuno Buenos Aires. 2015.

TRAVERSA, O. "Las tapas de los periódicos como dispositivo: Una discusión crítica". En: Encrucijadas, $\mathrm{N}^{\circ}$ 33. Universidad de Buenos Aires. 2005. Disponible en: http:repositoriouba.sisbi.uba.ar

TRAVERSA, O. "Martín Fierro como periódico". En: Noé Jitrik (dir.) Historia critica de la literatura argentina. Manzoni, C. (dir.) Rupturas (Vol. 7). Bs. As. Emecé. 2009.

TRAVERSA, O. Aproximaciones a la noción de dispositivo. Signo y Seña $\mathrm{N}^{\circ} 12$. Buenos Aires. Facultad de Filosofía y Letras UBA. 2001.

TRAVERSA, O. Inflexiones del discurso: cambios y rupturas en las trayectorias del sentido. Buenos Aires. Santiago Arcos Editor. 2014.

TRAVERSA, O. y MORÉ, M. Acerca de la construcción del cuerpo en el periodo 19401970: un curso de semiotización en los medios de prensa. Cuadernos $\mathrm{N}^{\circ} 17$. FHYCSUNJu. 2001

VERÓN, E. "El sentido como producción discursiva". En: Verón, E. La semiosis social. Fragmentos de una teoría de la discursividad. Barcelona. Gedisa. 1993.

VERÓN, E. "La materialidad del sentido". En: Verón, E. La semiosis social II. Bs. As. Paidós, 2013. 